\title{
Filtration reliability and safety of earth-fill dam
}

\author{
Khojiakbar Khasanov ${ }^{*}$, Kakhramon Babajanov ${ }^{2}$, and Nodira Babajanova ${ }^{1}$ \\ ${ }^{1}$ Tashkent institute of irrigation and agricultural mechanization engineers, Tashkent, Uzbekistan \\ ${ }^{2}$ GUP «Suvloyiha» Tashkent, Uzbekistan
}

\begin{abstract}
The study of the reliability and safety of the constructed earthfill dams and the comparison with their design and calculated data makes it possible to improve the structures and methods of the calculation substantiation of these structures. This work aims to study the filtration reliability and safety of the earth-fill dam of the Channel water reservoir of the Tuyamuyun hydroelectric complex (THC) on the Amu Darya River, which was put into exploitation in 1984. Field studies were carried out according to the traditional method using results of control and measuring equipment (CME) embedded in the body of the dam. The water levels of the upper and lower reaches, piezometers, and drainage water flow were measured. The maximum water levels upstream of 130.00 were observed in July-August and November 2017, and the minimum of 117.50 at the end of March. The water levels downstream depend on the value of the discharge through the hydrosystem. The maximum level downstream for 2017 was $112.55 \mathrm{~m}(01.06 .2017)$ with a flow rate of $2000 \mathrm{~m}^{3} / \mathrm{s}$. The minimum level downstream of $109.15 \mathrm{~m}$ was observed on November 29, 2017, when the discharge into the downstream through the hydroelectric complex was $260 \mathrm{~m}^{3} / \mathrm{s}$. A tendency to an increase in the level of the bottom downstream was found. Filling and depletion graphs of the Channel water reservoir have been built, from which it is found that they reached 2.00 $\mathrm{m} /$ day, and $1.60 \mathrm{~m} /$ day, respectively. This is 4 and 1.6 times more than the standard $0.5 \mathrm{~m} /$ day and $1.0 \mathrm{~m} /$ day. Of the 53 piezometers, 34 are working conditions; the rest do not work, require flushing. Graphs of water level changes in piezometers show that they change with an average 15-20 day delay in the water level in the Channel water reservoir. In general, the natural depression curve is below the design one. The maximum filtration flow rate was $63.3 \mathrm{l} / \mathrm{s}$ at a water level in the upper pool of 129.00 .
\end{abstract}

\section{Introduction}

Throughout its history, reservoirs formed due to river blockades have played an important role in societies around the world, regulating floods, generating hydroelectric power, and redistributing river water for irrigation.

Uzbekistan is a mostly arid region, where evaporation exceeds precipitation and annual precipitation is lower. This means that agricultural production is impossible without

*Corresponding author:kh.khasanov@mail.ru 
irrigation. So, the irrigation system is primarily one of the main economic development factors, employment, and food security in Uzbekistan.

Currently, there are 59 reservoirs in Uzbekistan; with the help of these facilities, the republic provides irrigation of agricultural land, utilities, industry, fishing, electricity production, etc. Of the operated reservoirs, 22 reservoirs have been in operation for 15-25 years, 26 reservoirs have been in operation for 25-25 years, and 11 reservoirs are over 60 years old. Most of the existing water reservoirs have been operating for 30-40 years, and during this period, their intensive sedimentation has taken place, and they lost a significant amount of their volume [1-3]. Out of all accidents of earth-fill dams, 33\% of them have occurred due to filtration [4-5].

Safe and reliable use of existing water reservoirs and construction of new ones are the important factor for the republic's economy. The sharp deficit of water resources in the region requires new and reconstructing existing water reservoirs. It is advisable to use modern technologies to construct new reservoirs and increase the size of existing ones [67].

Tuyamuyun hydroelectric complex, which carries a large amount of suspended sediment with turbidity up to $12 \mathrm{~kg} / \mathrm{m}^{3}$ is the first on the list [8-12]. At present, out of 2.34 billion $\mathrm{m}^{3}$ of the volume of Channel water reservoir, only $770 \mathrm{mln} . \mathrm{m}^{3}$ is left, i.e. sedimentation volume is $67 \%$ [13-15]. Therefore, special attention must be paid to field studies of existing Earth-fill dams to estimate the reliability and safety of their operation [16-19].

The purpose of this work is to study the filtration reliability and safety of the earth-fill dam of the Channel water reservoir of the Tuyamuyun hydroelectric complex on the Amu Darya River, which was put into exploitation in 1984' figure 1'. Field studies were carried out according to the traditional method using results of control and measuring equipment embedded in the body of the dam.

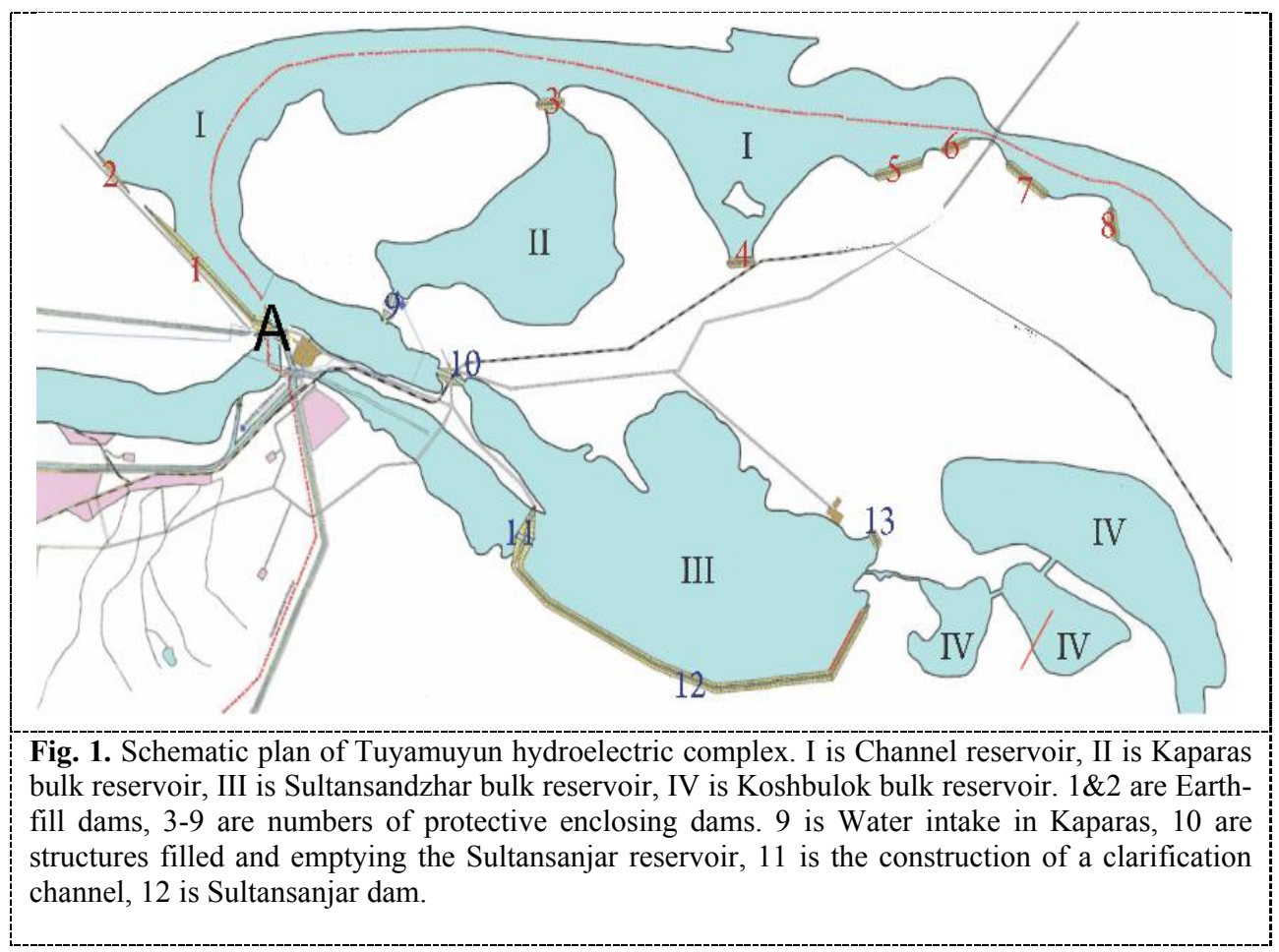




\section{Methods}

The following filtration parameters were controlled in earth-fill dam: a) phreatic line position in dam body; b) height of seepage of filtration flow in drainage devices or on the slope; c) filtration discharge in drainage lines, outlets from drains, and in outflow collectors.

Phreatic line position is determined using a network of piezometers, 1-2 times a week. During filling and draw-off of a water reservoir, observations are carried out daily

Filtration discharge in drains was determined with the use of water measuring posts, which are installed in all water outlet devices. Measurement of filtration discharge of water was carried out simultaneously with observations of phreatic line position. The measured value was compared with design values and with data from previous observations. Besides measurements of water level in piezometers and discharge of water in drains, the systematic observations included measurements of water level in the head race and tail race. Main field measurements of filtration processes were carried out by piezometers. To comment on the condition and reliability of installed piezometers in the process of operation by operating service, their operating sensitivity was also inspected. Piezometer sensitivity is characterized by the time needed to restore water level in it, changed to value $\mathrm{H}_{0}$ by filling or pumping out water. For non-pressure piezometers, restoration time of water level from $\mathrm{H}_{0}$ to $\mathrm{H}$ can be approximately determined using the following relationship:

$$
t=\frac{d^{2}}{4 K D} \cdot \frac{l_{n} \cdot H_{0}}{H}
$$

Where: $t$ is water level restoration time, sec: $d$ is piezometer pipe diameter, $\mathrm{cm}$ :

$\mathrm{D}$ is diameter of water inflow part, including back-filter, $\mathrm{cm}$;

$\mathrm{K}$ is base soil filtration coefficient near water inflow structure, $\mathrm{cm} / \mathrm{sec}$.

Piezometer can be considered sufficiently sensitive if the actual time of restoration is close to the value determined using the above relationship.

If the restoration time established by the experiment is higher than the determined value, then it may be considered that the piezometer is filled with sediment. If it is lower, it means that the piezometer has a leak.

Based on the analysis of turbidity samples, laboratory tests determine:

$>$ particle size distribution of material carried out into drainages and boreholes;

$>$ type and color of the material;

$>$ the origin of the material;

Under normal operation, sampling for turbidity is carried out once a month, to chemical analysis - once in a quarter year. If sharp deviations are noticed in the result of analyses from previous, sampling is carried out daily. Water level measurements in piezometers were carried out with an accuracy of $1 \mathrm{~cm}$. Piezometer water level observation data is used to construct chronologic plots of filtration regime for each piezometric section. Curves of water level change in the head race, structure profile by piezometric section with an indication of piezometer locations, soil properties, and geological structure of the section under consideration are plotted. Constructed chronological graphs for each of the measuring sections are compared with design phreatic lines.

Chronological graphs were constructed for filtrations discharges as well, determined in water measurement posts and turns. Constructed plots were compared with design plots. 


\section{Results and Discussions}

The Earth-fill dam of the Tuyamuyun hydroelectric complex includes the left-bank part, located on a rocky base, the channel part, and the right-bank part, located in the river floodplain, called the lengthening of the dam 'figure 1'.

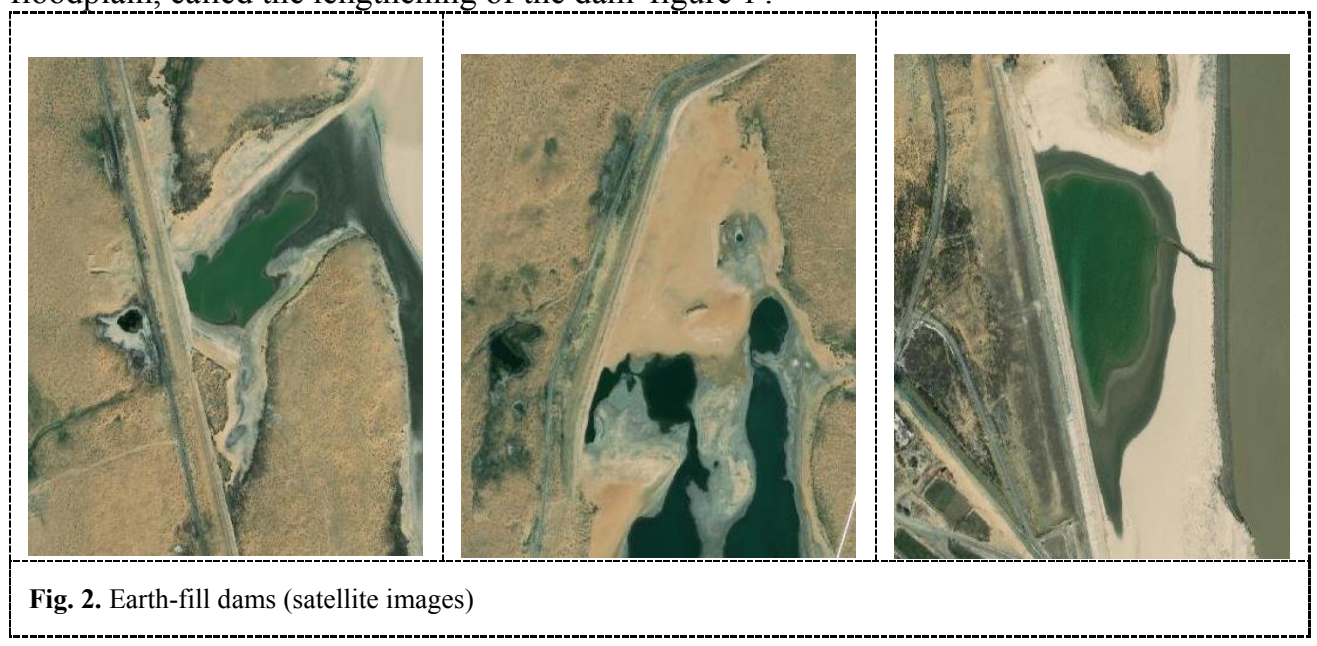

The alluvial Tertiary-Quaternary deposits of the Amu Darya serve as the dam's base in the channel and right-bank floodplains. Limestones and sandstones form the basis of a blind Earth-fill dam in the left-bank part.

To deflect filtration water at the tail race, 3 drain lines were installed. The first line gallery drain with incline filter at the slope, is the main drain, the second and the third lines - pipe drains, are auxiliary ones and intended to lower phreatic line at the site between the dam and right bank main canal (PMC).

The filtration regime in the Earth-fill dam is entirely determined by fluctuations in the water level in the Channel reservoir. Therefore they were first penetrated. Fluctuations in the water levels in the reservoirs of the Tuyamuyun hydroelectric complex changed as follows: the mark of $130.0 \mathrm{~m}$ on the Channel reservoir was set twice, in the second half of July and in the first half of August 2017, and the minimum water level of the Channel reservoir of $117.50 \mathrm{~m}$ was observed on 04/02/2017' figure 3 '. 


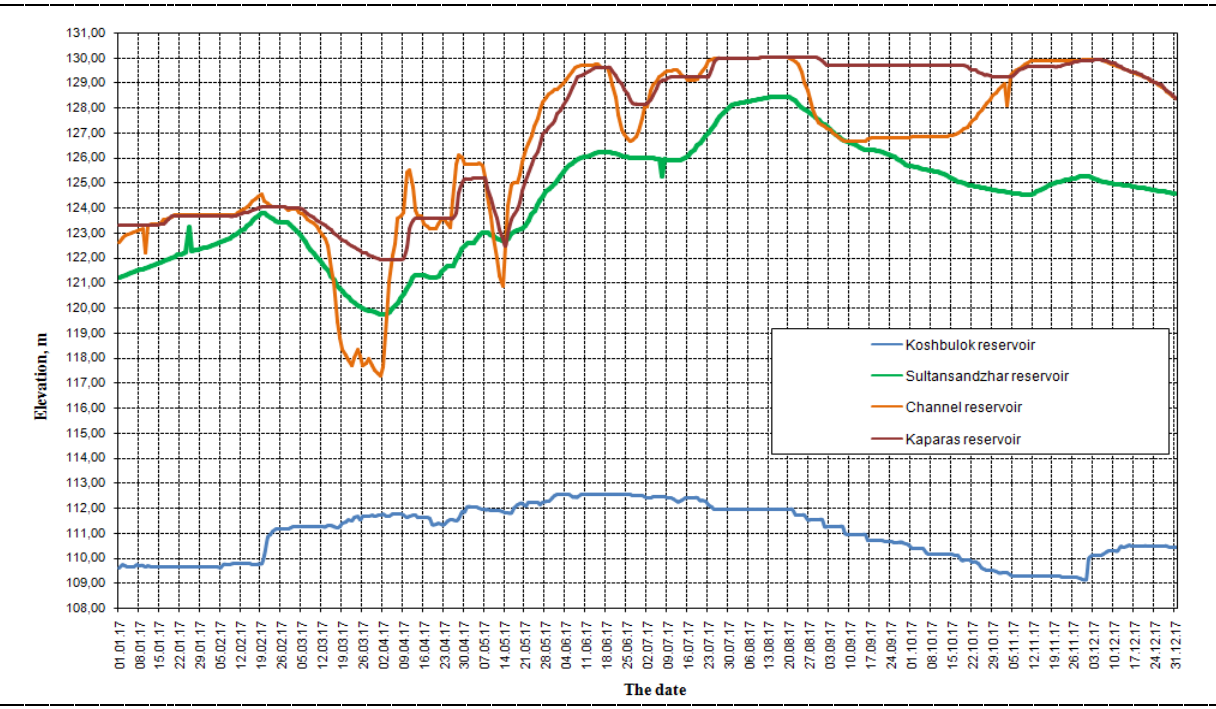

Fig. 3. Water level fluctuation plots for Tuyamuyun hydroelectric complex water reservoir for 2017.

The graph of changes in the rate of filling and drawdown of the channel reservoir is characterized by several peaks' figure 4' The maximum drawdown rate of the channel reservoir over the observation period was $1.60 \mathrm{~m}$ per day on March 17, 2017. There are still seven peaks from 0.8 to $1.00 \mathrm{~m}$ per day, the maximum rate the filling of the channel reservoir was $2.00 \mathrm{~m}$ per day on $04 / 02 / 2017$, and the graph has six more peaks from $1.05 \mathrm{~m}$ a day to $1.6 \mathrm{~m}$ a day, versus $0.5 \mathrm{~m}$ a day at drawdown and $1.0 \mathrm{~m}$ a day at filling, by the norm.

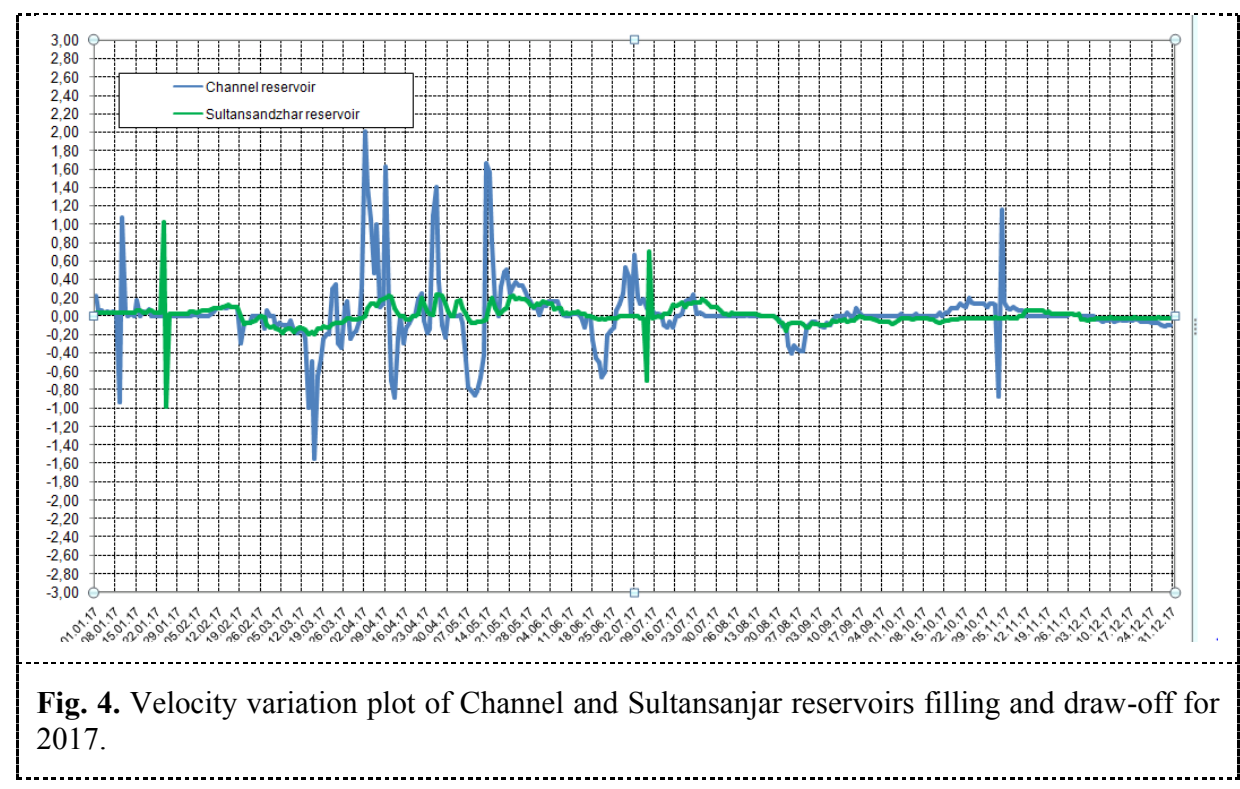

In the downstream, the fluctuation of levels depends on the flow of flow rates through hydraulic structures. The maximum level downstream for 2017 was $112.55 \mathrm{~m}(01.06 .2017)$ with a flow rate of $2000 \mathrm{~m}^{3} / \mathrm{s}$. The minimum downstream level of $109.15 \mathrm{~m}$ was observed 
on $11 / 29 / 2017$ when the discharge into the downstream through the hydroelectric complex was $260 \mathrm{~m}^{3} / \mathrm{s}$. The maximum daily increase in the downstream water level for the reporting period was $0.73 \mathrm{~m}(02 / 21 / 2017)$ with a daily increase in downstream discharge by $150 \mathrm{~m}^{3} / \mathrm{s}$ (from $300 \mathrm{~m}^{3} / \mathrm{s}$ to $450 \mathrm{~m}^{3} / \mathrm{s}$ ). The maximum daily decrease in the downstream water level was $0.22 \mathrm{~m}(19.04 .2017)$ with a decrease in a discharge into the downstream by $100 \mathrm{~m}^{3} / \mathrm{s}$ (from $500 \mathrm{~m}^{3} / \mathrm{s}$ to $400 \mathrm{~m}^{3} / \mathrm{s}$ ).

Downstream hydrograph and the curve of discharge versus water level in the downstream of the Tuyamuyun hydroelectric complex for 2016-2017 are shown in 'figure 5 '.

After plotting the curves of the dependence of the downstream level on the discharge for several years of observations, the curves of the graphs show an increase in the water level downstream compared with 2016. The difference in the passage of flow rates of about 150 $\mathrm{m}^{3} / \mathrm{s}-0.35 \mathrm{~m}$. And with the passage of flows of more than $1300 \mathrm{~m}^{3} / \mathrm{s}-0.85 \mathrm{~m}$, which indicates the gradual siltation of the river channel in the downstream and the bottom rise.

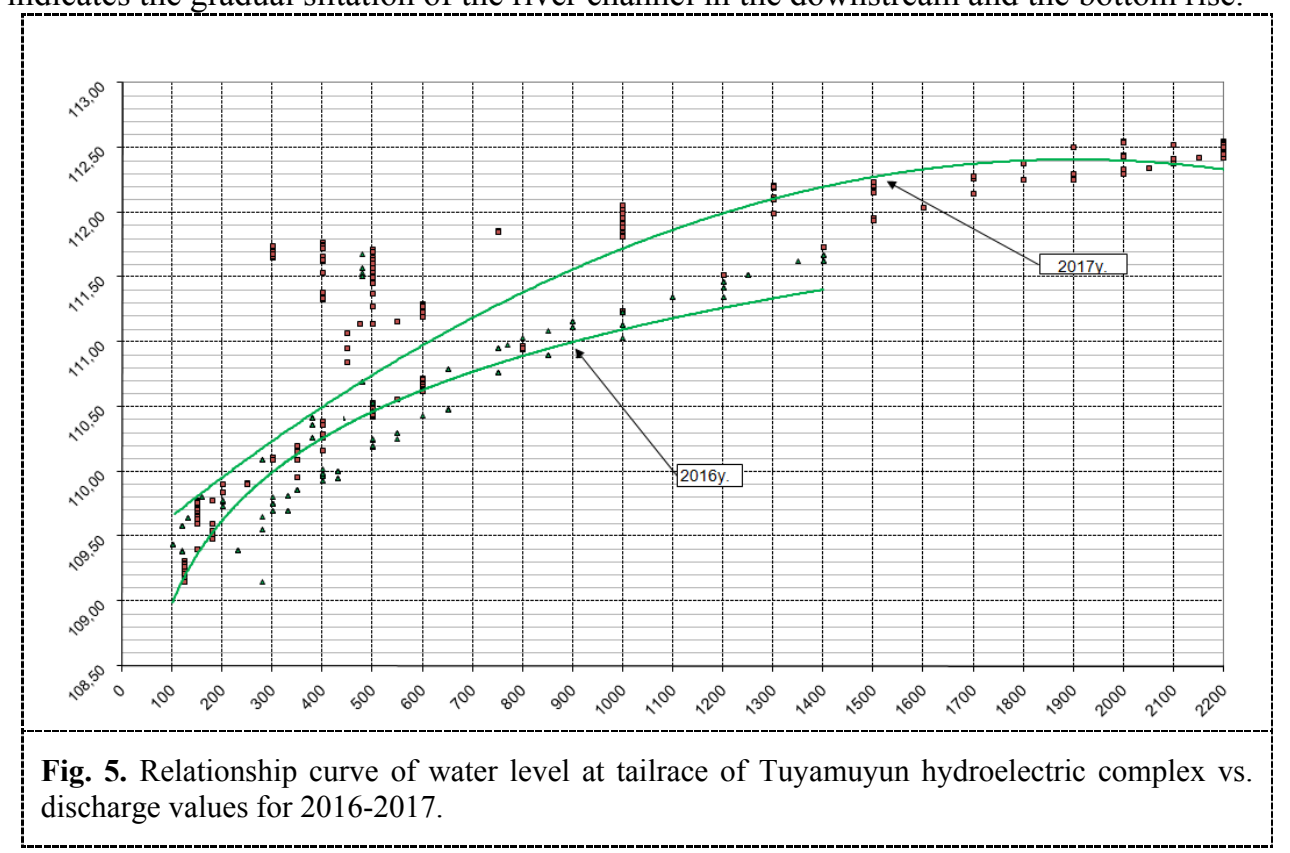

For observing structure condition, the following control measurement devices are installed in the dam: earth surface benchmarks, located in 8 cross-sections, in the amount of 91 signs; depth benchmarks at the same sections in the amount of 18 signs; submersed earth piezometers, located at the same sections, in the amount of 53 signs (34 of them are in operating condition); additional 79 benchmarks are installed above drainage gallery.

Piezometers № $1 ; 2 ; 3 ; 5 ; 6 ; 9 ; 10 ; 11 ; 13 ; 14 ; 15 ; 19 ; 20 ; 24 ; 26 ; 30$ are sediment filled, and piezometers № $4 ; 8 ; 16^{\mathrm{I}} ; 17^{\mathrm{I}} ; 18^{\mathrm{I}} ; 21^{\mathrm{I}}$ are clogged 


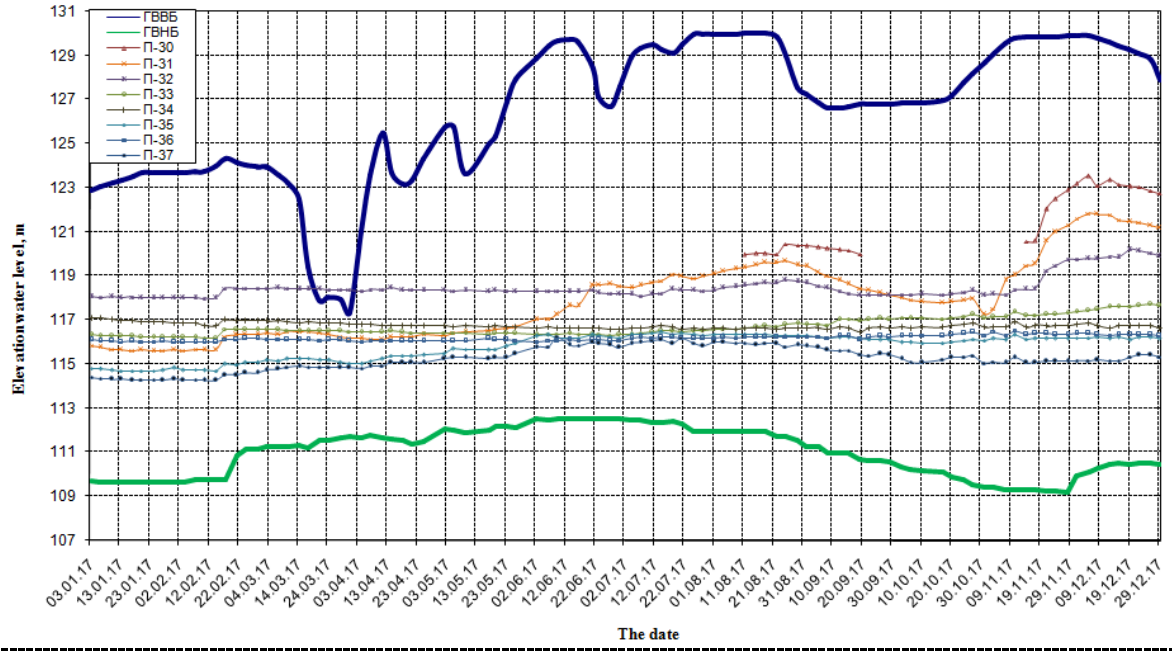

Fig. 6. Fluctuation plots of water levels in earth-fill dam piezometers, section №6 P.K. 6+67.8

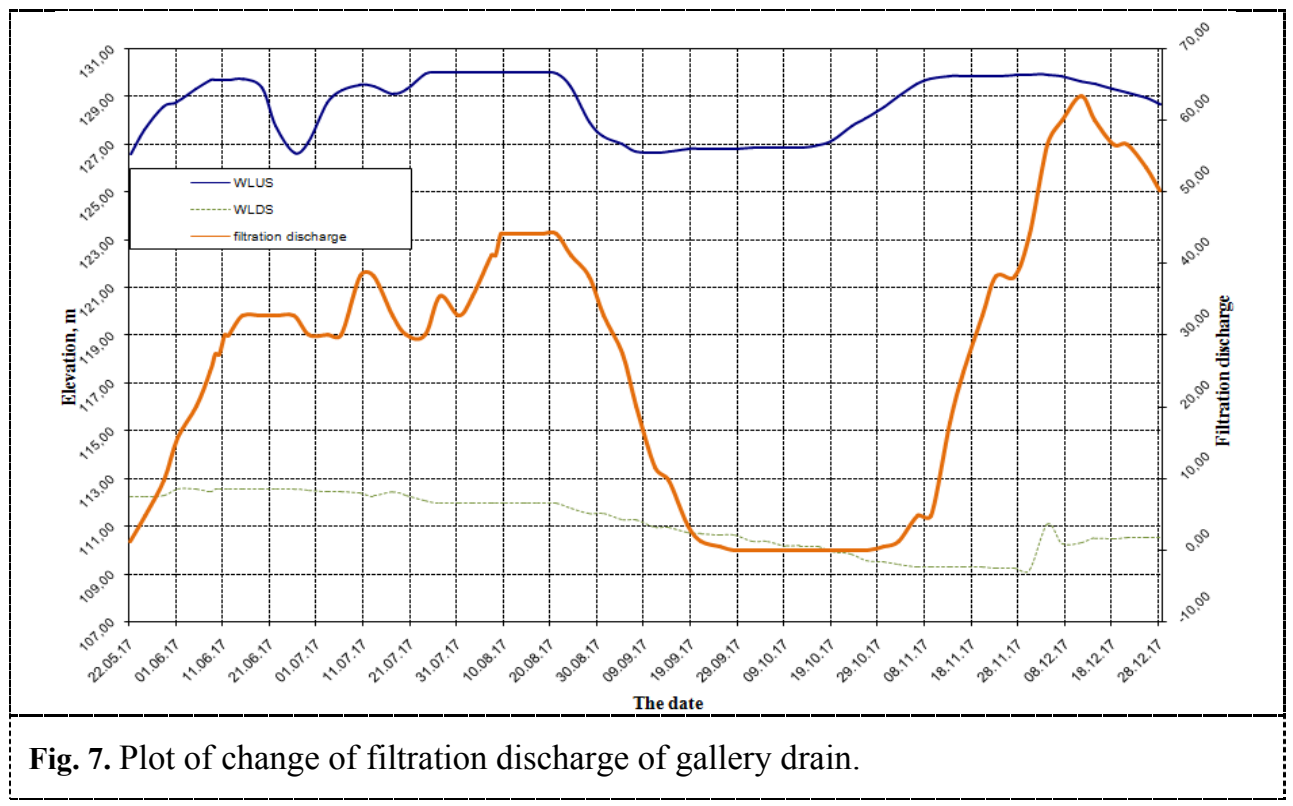

Filtration discharges of Earth-fill dams directly depend on water fluctuations at the head race and don't have sudden jumps. Quantitative indicators don't exceed values for previous years of observation. Most of the piezometers in Earth-fill dam react to fluctuations of water level at head race very slowly or don't react at all. Long-term observations have established that the filtration flow rate (maximum values) tends to decrease. No particles were carried out in the gallery drainage of the earth dam during the study period. 


\section{Conclusions}

To improve the reliability and safety of an Earth-fill dam, it is recommended to improve the quality of measurements in piezometers of the pressure front structures; all piezometers must be revised, faulty piezometers must be repaired; piezometers with leaks should be excluded from the process of field observations; observers must be technically competent and conscientious; strictly observe the schedules for measuring filtration flow rates and pressures at the base of structures.

To improve the reliability and safety of the earthen dam, it is necessary to repair and restore the missing control and measuring equipment, to observe the composition and frequency of field observations in accordance with the project of the organization of operation and operating instructions.

During 2017, the maximum discharge rate of the channel reservoir was $1.6 \mathrm{~m} /$ day. The filling rate was $2.0 \mathrm{~m} /$ day, which can provoke the appearance of unsteady filtration in the body of the earthen dam and a decrease in its filtration reliability and safety. It is not allowed to exceed the rates of filling and actuation higher than the values established by the project: permissible filling rate $-1.0 \mathrm{~m} /$ day, permissible actuation rate $-0.5 \mathrm{~m} /$ day.

\section{References}

1. Sh.Rakhmatullaev et al. Water 2, (2009)

2. Sh.Rakhmatullaevet al. Environmental Earth Sciences 68, (2013)

3. Sh.Rakhmatullaevet al. India. IAHS Publ., (2011)

4. Bakiev M., Kirillova E., Khujakulov R. Safety of hydrotechnical structures. TIIAME. Tashkent. 278p (2008)

5. Bakiev M., Kaveshnikov N., Tursunov T. Use of hydraulic structures TIIAMI, 442p (2008)

6. K. Khasanov, "Evaluation of ASTER DEM and SRTM DEM data for determining the area and volume of the water reservoir," IOP Conf. Ser. Mater. Sci. Eng., vol. 883, Jul. 2020, doi: 10.1088/1757-899X/883/1/012063.

7. M. Bakiev and K. Khasanov, "Comparison of Digital Elevation Models for Determining the Area and Volume of the Water Reservoir," Int. J. Geoinformatics, vol. 17 , no. 1, pp. 37-45, Feb. 2021,

8. O.Olsson et al. Irrigation and Drainage Systems. 25(1), (2011)

9. JochenFroebrich, Melanie Bauer, MalikaIkramova, Oliver Olsson. Environmental science and pollution research international. 14(6), (2007)

10. Ikramova M.R. Runoff regulation and reorganization of channels of plain rivers. Abstract Diss. Doctor of Technical Sciences (DSc).TIIAME. Tashkent. p. 32 (2019)

11. Davronov G. T., Firlina G.L. YoungScientist. 23(127), (2016)

12. M. Bakiev et al. IOP Conf. Series: Materials Science and Engineering 883, 012008 (2020)

13. Duhovny V. A., Sorokin D. A. Research report. SIC ICWC.Tashkent. 40p (2016)

14. Bazarov D.R. "Scientific justification of new numerical methods for calculating channel deformations of rivers, the channel of which is composed of easily eroded soils. Thesis for the degree of Doctor of Technical Sciences" 2000 http:www.dissercat.com

15. E.Kurbanbaev, O.Artykov, S.Kurbanbaev, Integrated water resources management in the Amu Darya River Delta. GWP CAC. Tashkent. 145p (2010)

16. Aravin V.I., Nosova O.N. Field studies of filtration. Energy, Leningrad branch, p. 256, (1969) 
17. Yuldasheva K.A. Experience in combating siltation of a reservoir (review). SIC ICWC. Tashkent. 73p (2011)

18. Fisenko V.F. Control of the safe operation of hydraulic structures of channel medium-pressure hydroelectric power plants http://www.dissercat.com 218p (2008)

19. Yurov V.M. Improving control methods for operating modes of two reservoirs as part of a single water regulation complex: on the example of the river. White.dissercat.com, Ufa, (2014) 